\title{
Research
}

\section{Identifying primary care quality indicators for people with serious mental illness:}

\author{
a systematic review
}

\begin{abstract}
Background

Serious mental illness (SMI) — which comprises long-term conditions such as schizophrenia, bipolar disorder, and other psychoses - has enormous costs for patients and society. In many countries, people with SMI are treated solely in primary care, and have particular needs for physical care.
\end{abstract}

\section{Aim}

The objective of this study was to systematically review the literature to create a list of quality indicators relevant to patients with SMI that could be captured using routine data, and which could be used to monitor or incentivise better-quality primary care.

\section{Design and setting}

A systematic literature review, combined with a search of quality indicator databases and guidelines.

\section{Method}

The authors assessed whether indicators could be measured from routine data and the quality of the evidence.

\section{Results}

Out of 1847 papers and quality indicator databases identified, 27 were included, from which 59 quality indicators were identified, covering six domains. Of the 59 indicators, 52 could be assessed using routine data. The evidence base underpinning these indicators was relatively weak, and was primarily based on expert opinion rather than trial evidence.

\section{Conclusion}

With appropriate adaptation for different contexts, and in line with the relative responsibilities of primary and secondary care, use of the quality indicators has the potential to improve care and to improve the physical and mental health of people with SMI. However, before the indicators can be used to monitor or incentivise primary care quality, more robust links need to be established, with improved patient outcomes.

\section{Keywords}

pay-for-performance schemes; primary care quality indicators; serious mental illness: systematic review.

\section{INTRODUCTION}

Serious mental illness (SMI) includes schizophrenia, bipolar disorder, and other psychoses (defined by International Classification of Diseases [ICD-10] categories F20-F31, and including schizophrenia spectrum and other psychotic disorders together with bipolar and related disorders in DSM-5). ${ }^{2}$ SMI is linked with poor health outcomes, high healthcare costs, and high disease burden. ${ }^{3,4}$ People with SMI have, on average, a 20-year lower life expectancy, mostly due to preventable causes. ${ }^{5-8}$ The global morbidity study attributed $3.5 \%$ of total years lost to disability to schizophrenia and bipolar disorder combined. ${ }^{9} \mathrm{SMI}$ is also associated with increased treatment costs ${ }^{10}$ and hospitalisations. Yet, around a third of people with SMI in the UK are treated solely in primary care, ${ }^{11}$ and are in longterm contact with primary care services more often than the general population. ${ }^{12,13}$ Even in countries with very well developed secondary mental health care systems, primary care can make a key contribution to the care of people with SMI. ${ }^{14}$ The quality of primary care for people with mental health problems is therefore of international concern. ${ }^{15,16}$

In the UK, a national pay-for-performance scheme, the Quality and Outcomes Framework (QOF), exists to financially reward

C Kronenberg, MSc, $\mathrm{CINCH}$, health economist, National Research Center for Health Economics, University of Duisburg-Essen, Essen, Germany. T Doran, MD, MPH, MFPH, professor of health policy; M Goddard, MSc, director of centre for health economics; S Gilbody. DPhil, FRCPsych, director of mental health and addictions research group, Department of Health Sciences; R Jacobs, $\mathrm{PhD}$, professor of health economics, Centre for Health Economics, University of York, Heslington, York, UK. T Kendrick, MD, FRCPsych, FRCGP professor of primary care, Primary Care and Population Sciences, University of Southampton, Southampton, UK. CR Dare, expert by experience, UK. L Aylott, expert by experience, UK family practices for achieving quality targets for patients with long-term conditions. The $\mathrm{SMI}$ quality indicators in the QOF cover both mental health specific care (for example, monitoring lithium levels) and more general physical care (such as routine health checks). QOF indicators are for high-priority disease areas for which primary care has principal responsibility for ongoing care, and where there is good evidence that improved primary care will have health benefits. However, the QOF may neglect important unmeasured aspects of quality of care, ${ }^{17}$ and the incentives may result in tunnel vision, ${ }^{18}$ or a focus on activities that are prioritised at the expense of other non-incentivised activities. ${ }^{19,20}$ For example, the QOF focuses more on physical than mental health, because this is generally easier to measure.

The authors performed a systematic review of the literature and interrogated international databases to identify potential quality indicators that could supplement or replace indicators already included in the QOF for people with SMI, and which could potentially be incentivised in primary care. The authors included indicators that appeared in earlier versions of the QOF but were subsequently dropped from the scheme when it was reduced in scope to reduce workload. These indicators were included on the grounds that they remain valid measures of quality of care, and

\section{Address for correspondence}

Rowena Jacobs, Centre for Health Economics, University of York, Heslington, York, Y010 5DD, UK. E-mail: rowena.jacobsdayork.ac.uk

Submitted: 10 November 2016; Editor's response: 20 December 2016; final acceptance: 8 March 2017

\section{QBritish Journal of General Practice}

This is the full-length article (published online 4 Jul 2017) of an abridged version published in print. Cite this version as: Br J Gen Pract 2017; DOI: https://doi.org/10.3399/bjgp17X691721 


\section{How this fits in}

This is the first systematic review of indicators of primary care quality for patients with serious mental illness (SMI). The study identifies 59 quality indicators in six domains, the majority of which could be monitored using routine primary care data. A key domain is the focus on physical health care. Consideration of the use of a broad set of quality of care indicators may support the improvement of the mental and physical health of this patient group.

continue to be included in the broader National Institute for Health and Care Excellence (NICE) indicators menu. A major focus of the analysis was the source of the data on which the indicators were based. Those requiring primary data collection - for example, via surveys of patients or health professionals, or retrospective auditing of patient records - would be very challenging to incorporate into incentive schemes such as the QOF, whereas those based on routinely available data would, in principle, be more feasible to establish.

Previous literature reviews on quality indicators have focused on SMI in

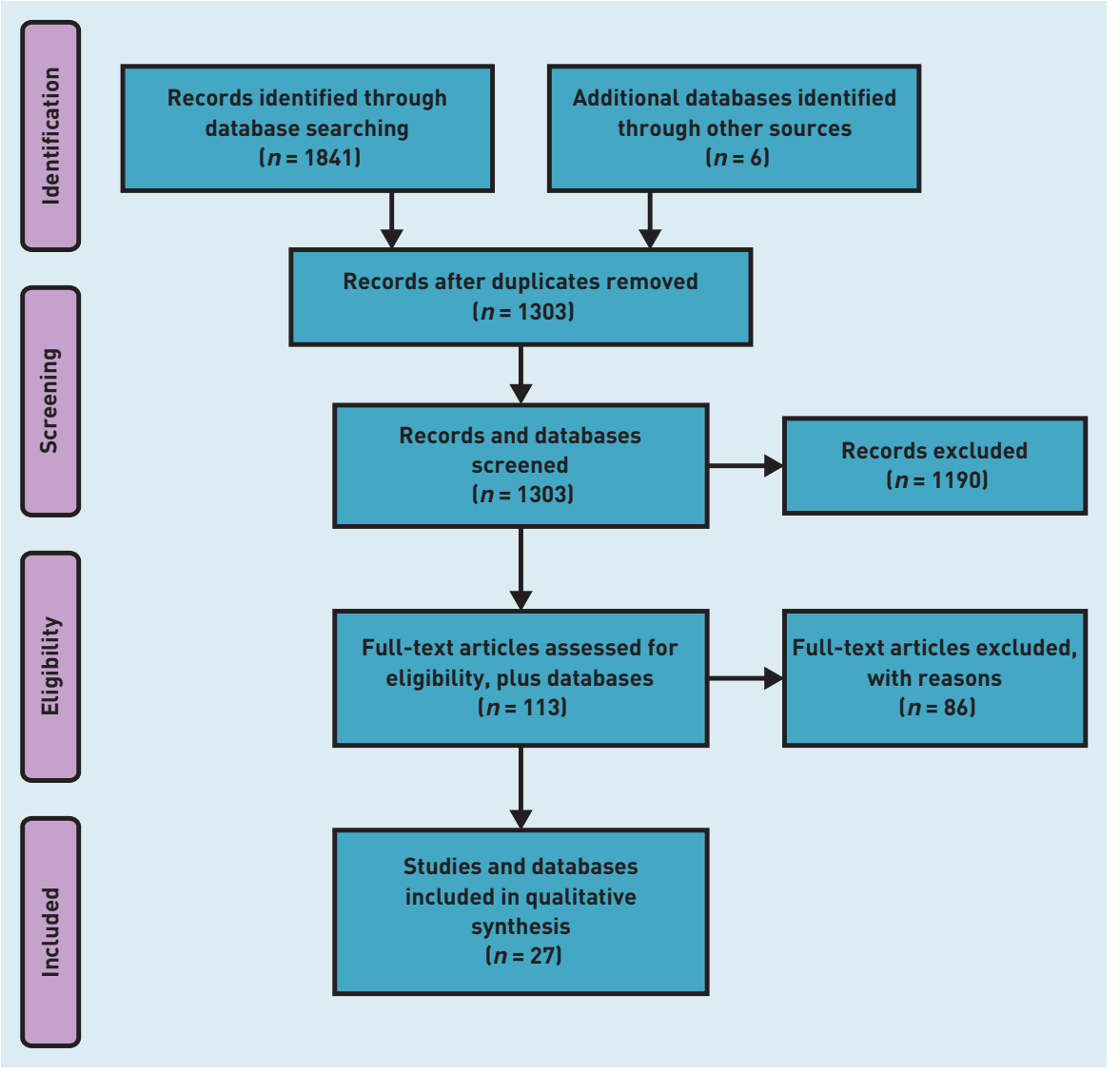

secondary care, ${ }^{22,23}$ whereas this study (to the authors' knowledge) is the first to focus specifically on people with SMI in primary care. Identifying indicators of primary care quality for people with SMI could help to strengthen the evidence base and shed light on neglected areas of care, as well as providing the basis for incentive schemes aimed at improving quality.

\section{METHOD}

A systematic review of primary care quality indicators for people with SMI was conducted with the aim of identifying quality indicators in addition to those already included in the QOF, either in the past or currently.

\section{Inclusion and exclusion criteria}

The authors searched for published examples of potential quality indicators that could readily be collected in primary care with reference to routine data. Search terms were identified by an information specialist in conjunction with the project team. Included papers had the terms serious mental illness AND primary care AND quality indicator, including alternative spellings and synonyms. Studies on children or covering non-psychotic illnesses, for example, severe depression or anxiety disorders, were excluded. All studies from January 1990 to February 2015 were considered for inclusion. No language restrictions were applied, although all search terms were in English, and all studies in English, German, Dutch, and Afrikaans were considered due to authors' language knowledge. The base search was constructed using MEDLINE and adapted to the other resources. The following databases were searched: Applied Social Sciences Index and Abstracts (ASSIA); CENTRAL; Cochrane Database of Systematic Reviews; Conference Proceedings Citation Index-Science (CPCl-S); Database of Abstracts of Reviews of Effects (DARE); EMBASE; Ovid MEDLINE ${ }^{\circledR}$ In-Process \& Other Non-Indexed Citations and Ovid MEDLINE ${ }^{\circledR}$; PsycINFO; and MEDLINE. The full strategy for MEDLINE as a template is available in Appendix 1.

Additionally, previous reviews with overlapping aims were searched, and authors were contacted to ask for their indicators (most notably Stegbauer et al ${ }^{22}$ and Großimlinghaus et a ${ }^{24}$. The quality indicator database of the Agency for Healthcare Research and Quality $(\mathrm{AHRQ})^{25}$ was also searched for indicators relevant to primary care. The final selection of indicators was informed by the views of the study steering committee, which included service users. 
Table 1. Quality of care indicators identified for people with serious mental illness

\begin{tabular}{|c|c|c|c|c|c|}
\hline Number & Description & Data source & QOF & AHRQ & References \\
\hline \multicolumn{6}{|c|}{ Coordination of care } \\
\hline 1 & Coordinated care - identify key worker (social worker or CPN) & Routine data & & & 26 \\
\hline 2 & $\begin{array}{l}\text { Staff continuity - good communication between staff and infrequent } \\
\text { staff changes }\end{array}$ & Routine data & & & 27 \\
\hline 3 & $\begin{array}{l}\text { Continuity: CONNECT is a patient questionnaire with } 72 \text { items, each rated on } \\
\text { a five-point scale, with } 13 \text { scales and one single-item indicator: } \\
\text { General coordination - 'Overall, is your mental health treatment } \\
\text { well coordinated?' Primary care scales - 'How often is psychiatrist in contact } \\
\text { with your primary care doctor?' (Never, Rarely, Sometimes, Often, Always) }\end{array}$ & Primary data & & & 28 \\
\hline 4 & Total number of follow-up contacts during treatment episode after initial evaluation & Routine data & & & 29 \\
\hline \multicolumn{6}{|c|}{$\begin{array}{ll} & \text { Substance misuse }\end{array}$} \\
\hline 5 & Patients with SMI who smoke who are offered tobacco counselling/help to stop smoking & Routine data & & & 25,30 \\
\hline 6 & Alcohol misuse screening & Routine data & $\checkmark$ & $\checkmark$ & 25 \\
\hline 7 & Screening for illicit drug use, type, quantity, and frequency & Routine data & & $\checkmark$ & 25 \\
\hline 8 & Referral to substance misuse disorder specialty care, if appropriate & Routine data & & & 23 \\
\hline 9 & HIV screening with co-occurring substance misuse for SMI service users & Routine data & & & 31 \\
\hline \multicolumn{6}{|c|}{ Service provision and access to care } \\
\hline 10 & Practice can produce register of all SMI patients & Routine data & $\checkmark$ & & 32 \\
\hline 11 & Service user registration with a primary health organisation & Routine data & & & 23 \\
\hline 12 & $\begin{array}{l}\text { Markers of care recorded: contact with secondary health services, written care } \\
\text { plans, 6-month mental health review, identified care coordinator, evidence of physical } \\
\text { examination }\end{array}$ & Routine data & $\checkmark$ & & 33 \\
\hline 13 & $\begin{array}{l}\text { Patients who do not attend the practice for their annual review who are identified and } \\
\text { followed up by the practice team }\end{array}$ & Routine data & $\checkmark$ & $\checkmark$ & 25 \\
\hline 14 & System contact: number of patients in contact with the treatment system & Routine data & & & 23 \\
\hline 15 & Surveillance to prevent relapse & Routine data & & & 27 \\
\hline 16 & Crisis management and out-of-hours services & Routine data & & & 28 \\
\hline 17 & Access to services and range of services & Routine data & & & 27 \\
\hline 18 & Family care - record of families living with person with schizophrenia & Primary data & & & 26 \\
\hline 19 & Duration of untreated psychosis: number of recently diagnosed patients & Routine data & & & 23,34 \\
\hline 20 & Waiting time between registration and start of treatment & Routine data & & & 23 \\
\hline \multicolumn{6}{|c|}{ Medicines management } \\
\hline 21 & $\begin{array}{l}\text { All current medication clearly available at all consultations - known drug dosages, } \\
\text { frequencies, history of side effects, review date }\end{array}$ & Primary data & & & 26 \\
\hline 22 & Monitor patients suffering extra pyramidal effects, check compliance & Routine data & & & 35 \\
\hline 23 & Assess weight gain, use of concomitant medication & Routine data & $\checkmark$ & & 36 \\
\hline 24 & Use of lithium: plasma lithium levels monitored regularly & Routine data & $\checkmark$ & & 37,38 \\
\hline 25 & Percentages of bipolar service users prescribed antidepressants and anxiolytics & Routine data & & & 37,38 \\
\hline 26 & $\begin{array}{l}\text { Proportion of patients who are receiving depot antipsychotics who have appropriate } \\
\text { laboratory screening tests }\end{array}$ & Routine data & $\checkmark$ & & 25 \\
\hline 27 & $\begin{array}{l}\text { Patients have their antipsychotic medication reviewed regularly, considering symptoms } \\
\text { and side effects: appropriate referral to specialist }\end{array}$ & Routine data & & & 39,40 \\
\hline 28 & $\begin{array}{l}\text { Polypharmacy: reduce number of patients using more than four psychotropic drugs } \\
\text { at the same time }\end{array}$ & Routine data & & & 41 \\
\hline 29 & Monitoring patients with neurological, sexual, sleeping, and sedation side effects & Routine data & & & 42 \\
\hline \multicolumn{6}{|c|}{ Mental health assessment and care } \\
\hline 30 & Percentage of patients given annual mental health review by GP & Routine data & $\checkmark$ & & 43 \\
\hline 31 & $\begin{array}{l}\text { Comprehensive mental status examination and history conducted in patients with a } \\
\text { new treatment episode }\end{array}$ & Routine data & $\checkmark$ & & 25.26 \\
\hline 32 & Referral for specialist mental health assessment & Routine data & & & 37 \\
\hline
\end{tabular}




\section{Table 1 continued. Quality of care indicators identified for people with serious mental illness}

\begin{tabular}{|c|c|c|c|c|c|}
\hline 33 & Comprehensive assessment of comorbid psychiatric conditions and response to treatment & Routine data & & $\checkmark$ & 25 \\
\hline 34 & Reassess severity of symptoms & Routine data & $\checkmark$ & & 44 \\
\hline 35 & Examined for duration of untreated psychosis & Primary data & & & 34 \\
\hline 36 & Delayed diagnosis & Primary data & & & 45 \\
\hline 37 & Informal carer contacts & Primary data & & & 27 \\
\hline \multirow[t]{2}{*}{38} & Information on employment status & Primary data & & & 26 \\
\hline & \multicolumn{5}{|c|}{ Physical health assessment and care } \\
\hline 39 & Diabetes monitoring for people with diabetes and schizophrenia & Routine data & & $\checkmark$ & 25 \\
\hline 40 & Diabetes and cholesterol monitoring for people with schizophrenia and diabetes & Routine data & & $\checkmark$ & 25 \\
\hline 41 & Diabetes screening for people who are using antipsychotic medications & Routine data & & $\checkmark$ & 25 \\
\hline 42 & Blood pressure screening for patients with diabetes & Routine data & $\checkmark$ & $\checkmark$ & $25,46-49$ \\
\hline 43 & Weight management/BMI monitoring & Routine data & $\checkmark$ & $\checkmark$ & $25,46-49$ \\
\hline 44 & Proportion with increased BMI/abdominal waistline & Routine data & $\checkmark$ & $\checkmark$ & $25,46-49$ \\
\hline 45 & $\begin{array}{l}\text { Patients with diabetes who received education about diabetes, nutrition, cooking, } \\
\text { physical activity, or exercise }\end{array}$ & Routine data & & $\checkmark$ & 25 \\
\hline 46 & Counselling on physical activity and/or nutrition for those with documented elevated BMI & Routine data & $\checkmark$ & $\checkmark$ & 25 \\
\hline 47 & Retinal exam for patients with SMI who have diabetes & Routine data & & $\checkmark$ & 25 \\
\hline 48 & Foot exam for patients with SMI who have diabetes & Routine data & & $\checkmark$ & 25 \\
\hline 49 & $\begin{array}{l}\text { Hypertension counselling: patients with hypertension who received education services } \\
\text { related to hypertension, nutrition, cooking, physical activity, or exercise }\end{array}$ & Routine data & & $\checkmark$ & 25 \\
\hline 50 & $\begin{array}{l}\text { Hypertension: recording and monitoring patients with hypertension and high blood } \\
\text { cholesterol (LDL) }\end{array}$ & Routine data & $\checkmark$ & $\checkmark$ & $25,46-49$ \\
\hline 51 & Breast cancer screening for women & Routine data & & $\checkmark$ & 25 \\
\hline 52 & Colorectal cancer screening & Routine data & & $\checkmark$ & 25 \\
\hline 53 & Proportion of patients who have an increased blood pressure & Routine data & $\checkmark$ & $\checkmark$ & $25,46-49$ \\
\hline 54 & Proportion of patients who have an increased blood glucose level & Routine data & $\checkmark$ & $\checkmark$ & 25 \\
\hline 55 & Proportion of patients who have low levels of glycosylated haemoglobin & Routine data & $\checkmark$ & $\checkmark$ & 25 \\
\hline 56 & Proportion of patients who have increased level of blood lipids & Routine data & & & 22 \\
\hline 57 & Comprehensive physical health assessment with appropriate advice & Routine data & $\checkmark$ & & 44 \\
\hline 58 & $\begin{array}{l}\text { Patients with diabetes who received psychoeducation related to weight (BMI), } \\
\text { diabetes (blood glucose levels) }\end{array}$ & Routine data & & & 50 \\
\hline 59 & Medical attention for nephropathy & Routine data & & & 51 \\
\hline
\end{tabular}

$A H R Q=$ Agency for Healthcare Research and Quality. BMI = body mass index. CPN= community psychiatric nurse. $L D L=$ low-density lipoprotein. QOF= Quality and Outcomes

Framework. SMI= serious mental illness.

\section{Study selection}

Titles of papers were first reviewed by five authors, and all studies that had been identified as potentially relevant by two members of the research team were included in the abstract screening process. All abstracts were screened by six authors, and full papers were obtained if two members of the team judged the abstract potentially relevant or in scope, that is, covering serious mental illness, primary care, and quality indicators. Full papers were divided into four groups and independently reviewed by four pairs of authors. The focus of the selection was to identify papers that included relevant quality indicators that could be applied in primary care. It was evident that the definition of primary care varies between different countries, so the authors included indicators with elements of shared care between primary and specialist settings (for example, prescribing and monitoring of antipsychotic medication), while acknowledging that, in some countries, those indicators may be more applicable to secondary care.

The search strategy complied with the PRISMA checklist (Appendix 2).

\section{Data extraction and analysis}

From each paper, a short description of each indicator was extracted, and the descriptions for similar indicators were merged. After reviewing the general areas covered by the indicators, they were grouped into six 
Table 2. Quality of evidence of studies identifying quality of care indicators for people with serious mental illness

\section{Study}

Parameswaran

Spaeth-Rublee, Pincus $^{23}$

$\mathrm{NICE}^{37}$

NICE ${ }^{30}$

$A H R Q^{25}$

Lester, Tritter, Sorohan ${ }^{32}$

Sweeney, Rose, Clement, et a l27 $^{27}$

Ware, Dickey, Tugenberg,

McHorney ${ }^{28}$

Cerimele, Chan,

Chwastiak, et al ${ }^{29}$

Pincus, Spaeth-Rublee,

Watkins $^{44}$

Holden $^{26}$

Swartz, MacGregor ${ }^{31}$

Highet, McNair,

Thompson, et a ${ }^{45}$

Lader $^{35}$

Haro, Salvador-Carulla ${ }^{36}$

Caughey, Kalish Ellett, Wong ${ }^{38}$

Busch, Lehman,

Goldman, Frank ${ }^{39}$

Young, Sullivan,

Burnam, Brook ${ }^{40}$

Nayrouz, Ploumaki,

Farooq, et a ${ }^{41}$

McCullagh, Morley, Dodwell ${ }^{33}$

Rodgers, Black,

Stobbart, Fosteri3

Osborn, Nazareth,

Wright, King ${ }^{46}$

Yeomans, Dale, Beedle ${ }^{47}$

Mitchell, Delaffon, Lord ${ }^{48}$

Roberts, Roalfe,

Wilson, Lester 19

\section{Description of study}

Strength

of evidence ${ }^{a}$

656 measures of quality of mental health care identified in earlier work

3

are rated in importance, validity, and feasibility, using a modified Delphi process

NICE treatment guidelines for bipolar disorder

4

NICE treatment guidelines for schizophrenia

$A H R Q$ provides a database of quality indicators that was used during the grey

literature search

Focus groups with patients, GPs, and nurses were conducted to explore how to improve care in cases of acute mental health crises

Structured interviews were conducted with 167 individuals suffering from psychoses to establish a concept of service user-defined continuity of care

This study reports on the field testing of an interview-based measure of continuity of care

Narrative description of 740 primary care patients with bipolar who participated in an MHIP.

Quality of care outcomes were derived from patient disease registry

Discussion on the barriers to measuring quality of care in the mental health arena, combined with a short list of potential quality measures

This study audited 16 GPs on their care for 266 patients with schizophrenia and observed that the audit led to improved recording of a range of quality indicators

The authors of this paper argue that in South Africa the role of mental health nurses has

been altered to focus on violence, substance misuse, and HIV/AIDS, and should be refocused

on psychiatry care in the primary care setting

The author summarises the literature on quality of care in mental health services in

Norway in 2008-2009

Interviews with 49 patients with bipolar to describe experience in primary care in Australia.

Eight themes for improvement of the primary care experience are outlined

Expert review of the standards of care in schizophrenia to reduce side effects while achieving best treatment outcomes

Observational study following 11000 patients who were on or changing antipsychotic medication to determine the best course of treatment with respect to symptoms, quality of life, social functioning, and other outcomes

Development, expert review, and assessment of the evidence base for, and validity of, medication-related indicators of potentially preventable hospitalisations

Observational study examining trends in four measures of quality over time in the US

Uncontrolled study looking at differences in quality of care as variations from national guidelines

Evaluation of an integrated care approach between primary care and community care, focused on patients with SMI

This observational study looks at urban versus rural differences in quality of care

for psychoses, as well as the difference in quality of care conditional on contacts with secondary care

Audit of quality of care in 822 Scottish patients with schizophrenia

Randomised trial to evaluate the impact of a nurse-led treatment to improve screening for CVD in the SMI population

Evaluation of a computer-based physical health screening template versus NICE guidelines for the SMI population

A systematic review and meta-analysis of screening practices with respect to metabolic risks for patients with psychosis

A retrospective view of case notes in $22 \mathrm{GP}$ practices to determine whether patients with schizophrenia receive equitable physical health care 


\section{Table 2 continued. Quality of evidence of studies identifying quality of care indicators for people with serious}

mental illness

Mainz, Hansen,

Description of the Danish National Indicator Project, which intends to document and advance

Palshof, Bartels ${ }^{42}$ quality of care

Druss, Zhao,

The study compared diabetes performance measures in US Medicaid enrolees with and

2

Cummings, et al ${ }^{51}$ without mental comorbidity

${ }^{a}$ Quality of evidence ${ }^{51}$ is categorised as: 1. High - Cochrane or systematic review, randomised control trial. 2. Moderate - non-randomised control study or unsystematic review. 3. Low - expert opinion, uncontrolled studies. 4. Not applicable - measure was extracted from grey literature, for example, (non-lgovernment organisations' documents or databases. $A H R Q=$ Agency for Healthcare Research and Quality. CVD = cardiovascular disease. MHIP = mental health integration programme. NICE = National Institute for Health and Care Excellence. SMI = Serious mental illness.

domains lcoordination of care, substance misuse, service provision and access to care, medicines management, mental health assessment and care, and physical health assessment and care). The domains were selected by the research team, which included service users, as representing broad areas of service provision and care that were viewed as important and could encompass all the chosen indicators. Some of the indicators may overlap the domain description boundaries as they are not intended to be rigid boundaries. Given the main focus of the study, the authors decided whether each indicator could, in principle, be measured from routine data or whether primary data collection would be necessary. Furthermore, the authors checked whether the identified indicators had ever been included in the QOF. They also assessed the quality of the evidence of the included studies using an adaptation of the GRADE guidelines, ${ }^{52}$ and rated the quality of the evidence as high (systematic reviews or randomised control trials), moderate (nonrandomised control studies or unsystematic reviews), low (expert opinion or uncontrolled studies), or not applicable (measure was extracted from the grey literature).

\section{RESULTS}

In total, 1847 studies and further database sources were identified using the search. The split was ASSIA (34), CENTRAL (96), Cochrane (12), Conferences Proceedings (125), DARE (28), EMBASE (738), Ovid MEDLINE (537), PsycINFO (271), and six further database sources $\left(A H R Q,{ }^{25}\right.$ Stegbauer et al, ${ }^{22}$ Großimlinghaus et $a l_{1}^{24}$ Parameswaran et al, ${ }^{23}$ and NICE). ${ }^{30,37}$ After removing duplicates using bibliographic software (EndNote and Zotero), 1303 records remained. Title screening reduced this to 356, excluding those that were not about quality indicators, or primary care, or mental illness, or were not included in the definition of SMI (for example, depression or substance misuse disorders). Abstract screening reduced the records to 113 , with similar reasons for exclusion. Finally, from those 113 records, 86 were excluded, and 27 records were included in the review (Figure 1, PRISMA flow diagram). From these 27 records, a final set of 59 different indicators was extracted.

Table 1 shows the final list of indicators. Of the 59 indicators, 52 could potentially be assessed using routine data, and seven would require primary data collection from patients or professionals. Of these 59 indicators, 17 are, or have previously been, included in the QOF. A large proportion of the indicators relevant to primary care are in the physical health domain. Another large subset of indicators relate to the process of receiving care, for example, continuity of care, access to services, and frequency of contacts.

Table 2 shows the quality of evidence of the included studies from which the indicators were drawn. Two studies were rated as high quality (Cochrane or systematic review, randomised control trial); three as moderate (non-randomised study or unsystematic review); 19 as low quality (expert opinion, uncontrolled studies); and three were of uncertain quality, having been identified from the 'grey' literature (for example, (non-)government organisations' documents or databases).

Only a very few randomised control trials (RCTs) have evaluated quality indicators. Two RCTs were reviewed in Cimo et $a l_{1}^{50}$ producing evidence on the effectiveness of lifestyle interventions for people with type 2 diabetes and schizophrenia or schizoaffective disorder. However, more often, indicators were based on expert consensus or small cross-sectional studies.

Many of the indicators identified were derived from a database of indicators produced by the US Agency for Healthcare 
Research and Quality $(A H R Q),{ }^{25}$ and the strength of evidence underpinning the individual indicators is variable.

\section{DISCUSSION}

\section{Summary}

To the authors' knowledge, this is the first attempt to identify in a systematic way potential indicators of quality of primary care for people with SMI. Although the authors identify over 50 indicators that could potentially be captured and monitored using routine data, crucially, they note that the quality of the available evidence underpinning the indicators is relatively weak.

\section{Strengths and limitations}

The feasibility of collecting data for any set of quality indicators will vary across different healthcare systems. Many countries have insurance or other systems, which routinely collect activity data in primary care. Some indicators are likely to require more effort to collect (for example, patient questionnaires for perceived continuity of care), and in many cases even routine data collection can prove very challenging. This study focused specifically on finding indicators that could be monitored at relatively low cost to the healthcare system.

The list of quality indicators identified in this study is much broader and more encompassing than the current list of indicators contained in the QOF SMI domain. However, some of the criticisms inherent in the use of quality metrics would remain even if indicators from this broader list were adopted. These include: measuring only what can be measured (in routine data) at the expense of other measures that matter, for example, 'softer' measures such as the quality of relationships or the quality of communication; ${ }^{53}$ the risk of prioritising some activities at the expense of other non-incentivised activities; ${ }^{54,55}$ and the wider impacts of financial incentives and excessive measurement on provider motivation and behaviour. ${ }^{56}$ Moreover, there are gaps in the literature and in the indicators identified, meaning that the service user perspective is not well represented. There is also an absence of quality indicators around aspects of the social environment, such as the stability of housing for people with SMI. Although such factors are important, and may well influence health outcomes, the extent to which primary care could influence these factors may be very limited and hence it may not be appropriate to hold primary care practitioners responsible for improving quality in these domains. The authors also acknowledge that there is an extensive literature in related areas of research that will also refer to very similar quality indicators, ${ }^{57}$ but the search terms were designed to focus on the specific area of interest, and screened out studies where the focus was broader. Finally, the search excluded non-published indicators and those written in languages other than those listed earlier.

\section{Implications for research and practice}

In the UK, to be included in the QOF, quality indicators must be supported by NICE evidence-based clinical guideline recommendations or evidence from systematic reviews. This, along with the need to maintain a manageable panel of indicators, explains why the large majority of indicators identified are not currently part of the QOF. The downside of the QOF approach is that recommendations based on expert consensus are not put forward for inclusion, despite the fact that a body of informed experts would support a prima facie rationale for including them. In contrast, the combined views of experts and patients underpin bestpractice guidance for those commissioning mental health services in the UK, covering many of the domains identified in this review, suggesting scope for a similar approach to be taken with respect to the QOF ${ }^{58}$ The adoption of indicators based on expert and patient consensus must ultimately be supported by evidence on cost-effectiveness, but this also applies to indicators based on higher levels of evidence. ${ }^{59}$

Donabedian' $\mathrm{S}^{60}$ conceptual framework of quality of care suggests indicators can usually be divided into three subcategories: structure, process, and outcome measures. To date, the evidence for apparent process improvements under incentive schemes leading to improved patient outcomes is mixed. The vast majority of indicators included in this review relate to processes of care, and, although aspects of process are highly relevant, especially to patients, it is important to establish whether quality indicators also promote improved health outcomes. If so, there is a case for their inclusion in the QOF and other initiatives aiming to improve the care of people with SMI. For physical conditions, improvements in processes of care in primary care settings have been found to be associated with modest improvements in intermediate outcomes (for example, cholesterol levels) ${ }^{61}$ and quality of life, 62 but associations with patient outcomes such as emergency hospital admission are weaker. ${ }^{63}$ For serious mental illness, the evidence is much more limited and suggests that higher provider 
performance on processes may not be associated with better patient outcomes. ${ }^{17}$

Many of the indicators identified in the study relate to aspects of physical care. People with SMI are at higher risk of physical ill health Iparticularly diabetes, and cardiovascular and respiratory disease), so clearly focusing on these aspects could help reduce the associated excess morbidity and mortality. ${ }^{64}$ People with SMI are vulnerable, with significant needs for care that may be missed or undertreated, leading to years spent with disabling morbidity and premature mortality. Viron et al ${ }^{14}$ emphasised that, in the US, as elsewhere:

As frontline clinicians, primary care providers have the potential to reduce the health disparities experienced by this population.'

Consideration of the use of a broader set of quality indicators, including those focusing on physical care, may therefore be a positive step. Given the increased risk of diabetes, cardiovascular disease, and respiratory disease in this population, ongoing primary care for people with SMI should focus on disease prevention through tackling obesity and smoking. Similarly, a large set of indicators relate to processes of care, including ongoing contact with relevant services. Targeting comprehensive primary care to people with SMI can also play a crucial role in promoting their engagement with appropriate specialised mental and physical healthcare services, helping them to reach their full potential.

\section{Funding}

The National Institute for Health Services \& Delivery Research (HS\&DR) programme funded this research (project no. 13/54/40). The views and opinions expressed therein are those of the authors and do not necessarily reflect those of the HS\&DR programme, the National Institute for Health Research, the NHS, or the Department of Health.

\section{Ethical approval}

Not applicable.

\section{Provenance}

Freely submitted; externally peer reviewed.

\section{Competing interests}

The authors have declared no competing interests.

\section{Open access}

This article is Open Access: CC BY-NC 4.0 license (http://creativecommons.org/ licenses/by-nc/4.0/).

\section{Acknowledgements}

The authors would like to thank the following study steering committee members for their invaluable contributions to this review: David Daniel, Holly Taggart, Ceri Dare, Lauren Aylott, and Jane Dunning. The authors would like to thank Kate Lewis-Light (Centre for Reviews and Dissemination, University of York) who designed and ran the specialist information searches. The authors would also like to thank Harold Pincus and Constance Stegbauer for sharing their detailed list of quality indicators.

\section{Discuss this article}

Contribute and read comments about this article: bjgp.org/letters 


\section{REFERENCES}

1. World Health Organization. The 10th revision of the international classification of diseases and related health problems (ICD-10). Geneva: WHO, 1992.

2. American Psychiatric Association. Diagnostic and statistical manual of mental disorders (DSM-V). Arlington, VA: APA, 2014

3. Harrison G, Hopper K, Craig T, et al. Recovery from psychotic illness: a 15- and 25-year international follow-up study. Br J Psychiatry 2001; 178(6): 506-517.

4. Murray CJ, Richards MA, Newton JN, et al. UK health performance: findings of the Global Burden of Disease Study 2010. Lancet 2013; 381(9871): 997-1020.

5. Osborn DP, Levy G, Nazareth I, et al. Relative risk of cardiovascular and cancer mortality in people with severe mental illness from the United Kingdom's General Practice Research Database. Arch Gen Psychiatry 2007; 64(2): 242-249.

6. Miller BJ, Paschall III CB, Svendsen DP. Mortality and medical comorbidity among patients with serious mental illness. Psychiatr Serv 2006; 57(10): 14821487

7. Wahlbeck K, Westman J, Nordentoft M, et al. Outcomes of Nordic mental health systems: life expectancy of patients with mental disorders. $\mathrm{Br} \mathrm{J}$ Psychiatry 2011; 199(6): 453-458.

8. Harris M. General practice recruitment for schizophrenia prevention studies, Aust N Z J Psychiatry 2000; 34(Suppl): S137-S139; discussion S140-S134.

9. Vos T, Flaxman AD, Naghavi M, et al. Years lived with disability (YLDs) for 1160 sequelae of 289 diseases and injuries 1990-2010: a systematic analysis for the Global Burden of Disease Study 2010. Lancet 2012; 380(9859): 2163-2196.

10. Layard R. How mental illness loses out in the NHS. A report by the Centre for Economic Performance's Mental Health Policy Group. Centre for Economic Performance, LSE, 2012.

11. Reilly S, Planner C, Hann M, et al. The role of primary care in service provision for people with severe mental illness in the United Kingdom. PloS One 2012: 7(5): e36468.

12. Kai J, Crosland $A$, Drinkwater $C$. Prevalence of enduring and disabling mental illness in the inner city. Br J Gen Pract 2000; 50(461): 992-994.

13. Lang FH, Johnstone E, Murray G. Service provision for people with schizophrenia II. Role of the general practitioner. Br J Psychiatry 1997; 171(2): 165-168.

14. Viron M, Baggett $T$, Hill M, Freudenreich 0 . Schizophrenia for primary care providers: how to contribute to the care of a vulnerable patient population. Am J Med 2012; 125(3): 223-230.

15. World Health Organization. The world health report 2003: shaping the future. Geneva: WHO, 2003.

16. World Health Organization. WHO QualityRights tool kit: assessing and improving quality and human rights in mental health and social care facilities. Geneva: WHO, 2012.

17. Gutacker N, Mason AR, Kendrick T, Jacobs R. Does the quality and outcomes framework reduce psychiatric admissions in people with serious mental illness? A regression analysis. BMJ Open 2015; 5(4): e007342.

18. Smith P. On the unintended consequences of publishing performance data in the public sector. Int J Public Adm 1995; 18(2): 277-310.

19. Doran T, Kontopantelis E, Valderas JM, et al. Effect of financial incentives on incentivised and non-incentivised clinical activities: longitudinal analysis of data from the UK Quality and Outcomes Framework. BMJ 2011; 342: d3590.

20. Eggleston K. Multitasking and mixed systems for provider payment. J Health Econ 2005; 24(1): 211-223.

21. Moher D, Liberati A, Tetzlaff J, Altman DG. Preferred reporting items for systematic reviews and meta-analyses: the PRISMA statement. Ann Intern Med 2009; 151(4): 264-269.

22. Stegbauer C, Szecsenyi J, Bramesfeld A. Studien zur Evaluation ambulanter psychiatrischer Versorgung: Werden die Prioritäten psychisch kranker Menschen berücksichtigt? [Article in German]. Psychiat Prax 2015; 44(1): 13-20.

23. Parameswaran SG, Spaeth-Rublee B, Pincus HA. Measuring the quality of mental health care: consensus perspectives from selected industrialized countries. Adm Policy Ment Health 2015; 42(3): 288-295.

24. Großimlinghaus I, Falkai P, Gaebel W, et al. Entwicklungsprozess der DGPPNQualitätsindikatoren. [Article in German]. Der Nervenarzt 2013; 84(3): 350-365

25. Agency for Healthcare Research and Quality. $A H R Q$ - quality indicators. $A H R Q$, 2016. www.qualityindicators.ahrq.gov laccessed 23 May 2017).

26. Holden J. An audit of the care of 266 patients with schizophrenia in 16 general practices. Irish J Psychologic Med 1998; 15(2): 61-63

27. Sweeney A, Rose D, Clement S, et al. Understanding service user-defined continuity of care and its relationship to health and social measures: a crosssectional study. BMC Health Serv Res 2012; 12: 145.

28. Ware NC, Dickey B, Tugenberg T, McHorney CA. CONNECT: a measure of continuity of care in mental health services. Ment Health Serv Res 2003; 5(4): 209-221.

29. Cerimele JM, Chan Y-F, Chwastiak LA, et al. Bipolar disorder in primary care clinical characteristics of 740 primary care patients with bipolar disorder. Psychiatr Serv 2014; 65(8): 1041-1046

30. National Institute for Health and Care Excellence. Psychosis and schizophrenia in adults: prevention and management. CG178. London: NICE, 2014. https:// www.nice.org.uk/guidance/cg178 (accessed 23 May 2017).

31. Swartz L, MacGregor $\mathrm{H}$. Integrating services, marginalizing patients: psychiatric patients and primary health care in South Africa. Transcult Psychiatry 2002; 39(2): 155-172.

32. Lester H, Tritter JQ, Sorohan H. Managing crisis: the role of primary care for people with serious mental illness. Fam Med 2004; 36(1): 28-34.

33. McCullagh M, Morley S, Dodwell D. A systematic, confidential approach to improving community care for patients with non-affective psychosis. Prim Care Psychiatr 2003; 8(4): 127-130.

34. Ruud T. Mental health quality and outcome measurement and improvement in Norway. Curr Opin Psychiatry 2009; 22(6): 631-635

35. Lader M. Consensus statements on standards of care in schizophrenia. Prim Care Psychiatr 1997; 3(3): 145-149.

36. Haro JM, Salvador-Carulla L. The SOHO ISchizophrenia Outpatient Health Outcomel Study: implications for the treatment of schizophrenia. CNS Drugs 2006; 20(4): 293-301.

37. National Institute for Health and Care Excellence. Bipolar disorder: assessment and management. CG185. London: NICE, 2014. https://www.nice.org.uk/ guidance/cg185 laccessed 23 May 2017).

38. Caughey G, Kalisch Ellett L, Wong T. Development of evidence-based Australian medication-related indicators of potentially preventable hospitalisations: a modified RAND appropriateness method. BMJ Open 2014; 4(4): e004625.

39. Busch AB, Lehman AF, Goldman H, Frank RG. Changes over time and disparities in schizophrenia treatment quality. Med Care 2009; 47(2): 199-207.

40. Young AS, Sullivan G, Burnam MA, Brook RH. Measuring the quality of outpatient treatment for schizophrenia. Arch Gen Psychiatry 1998; 55(7): 611-617.

41. Nayrouz S, Ploumaki S, Farooq R, et al. Physical health problems in patients with severe mental illness: relationship between antipsychotic treatment and physical health. Eur Neuropsychopharmacol 2011; 21: S480-S481.

42. Mainz J, Hansen AM, Palshof T, Bartels PD. National quality measurement using clinical indicators: the Danish National Indicator Project. J Surg Oncol 2009; 99(8): 500-504

43. Rodgers J, Black G, Stobbart A, Foster J. Audit of primary care of people with schizophrenia in general practice in Lothian. Qual Prim Care 2003; 11(2): 133-140.

44. Pincus HA, Spaeth-Rublee B, Watkins KE. The case for measuring quality in mental health and substance abuse care. Health Affairs 2011; 30(4): 730-736.

45. Highet NJ, McNair BG, Thompson M, et al. Experience with treatment services for people with bipolar disorder. Med J Aust 2004; 181(7 Suppl): S47-S51.

46. Osborn DP, Nazareth I, Wright CA, King MB. Impact of a nurse-led intervention to improve screening for cardiovascular risk factors in people with severe mental illnesses. Phase-two cluster randomised feasibility trial of community mental health teams. BMC Health Serv Res 2010; 10: 61.

47. Yeomans D, Dale K, Beedle K. Systematic computerised cardiovascular health screening for people with severe mental illness. Psychiatr Bull 2014; 38(6): 280-284.

48. Mitchell AJ, Delaffon V, Lord O. Let's get physical: improving the medical care of people with severe mental illness. Adv Psychiatr Treat 2012; 18(3): 216-225.

49. Roberts L, Roalfe A, Wilson S, Lester H. Physical health care of patients with schizophrenia in primary care: a comparative study. Fam Pract 2007; 24(1): 34-40.

50. Cimo A, Stergiopoulos E, Cheng C, et al. Effective lifestyle interventions to improve type II diabetes self-management for those with schizophrenia or schizoaffective disorder: a systematic review. BMC Psychiatry 2012; 12(1): 24.

51. Druss BG, Zhao L, Cummings JR, et al. Mental comorbidity and quality of diabetes care under Medicaid: a 50-state analysis. Med Care 2012; 50(5): 
428-433

52. Balshem $H$, Helfand $M$, Schünemann $H J$, et al. GRADE guidelines: 3 . Rating the quality of evidence. J Clin Epidemiol 2011; 64(4): 401-406.

53. McDonald R, Harrison S, Checkland $\mathrm{K}$, et al. Impact of financial incentives on clinical autonomy and internal motivation in primary care: ethnographic study. BMJ 2007; 334(7608): 1357-1362.

54. Doran T, Kontopantelis E, Valderas J, et al. Effect of financial incentives on incentivised and non-incentivised clinical activities: longitudinal analysis of data from the UK Quality and Outcomes Framework. BMJ 2011; 342(1): d3590.

55. Kreif N, Grieve R, Hangartner D, et al. Examination of the synthetic control method for evaluating health policies with multiple treated units. Health Econ 2016; 25(12): 1524-1528.

56. Doran T. Incentivising improvements in health care delivery: a response to Adam Oliver. Health Econ Policy Law 2015; 10(3): 351-356.

57. Byng $\mathrm{R}$, Jones $\mathrm{R}$, Leese $\mathrm{M}$, et al. Exploratory cluster randomised controlled trial of shared care development for long-term mental illness. Br J Gen Pract 2004; 54(501): 259-266

58. Joint Commissioning Panel for Mental Health. Guidance for commissioners of primary mental health care services. JCPMH, 2012.
59. Doran T, Maurer KA, Ryan AM. Impact of provider incentives on quality and value of health care. Annu Rev Public Health 2016; DOI: 10.1146/annurevpublhealth-032315-021457.

60. Donabedian A. The quality of care: how can it be assessed? JAMA 1988 260(12): 1743-1748.

61. Ryan AM, Doran T. The effect of improving processes of care on patient outcomes: evidence from the United Kingdom's Quality and Outcomes Framework. Med Care 2012; 50(3): 191-199.

62. Kahn KL, Tisnado DM, Adams JL, et al. Does ambulatory process of care predict health-related quality of life outcomes for patients with chronic disease? Health Serv Res 2007; 42(1pt1): 63-83.

63. Flodgren G, Eccles MP, Shepperd S, et al. An overview of reviews evaluating the effectiveness of financial incentives in changing healthcare professional behaviours and patient outcomes. Cochrane Database Syst Rev 2011; 7(7): CD009255. DOI: 10.1002/14651858.CD009255.

64. Hoang U, Goldacre MJ, Stewart R. Avoidable mortality in people with schizophrenia or bipolar disorder in England. Acta Psychiatrica Scandinavica 2013; 127(3): 195-201 


\section{Appendix 1. Annotated search strategy (MEDLINE via OVID SP)}

\begin{tabular}{|c|c|}
\hline 1 serious mental illness*.tw. (2037) & 39 Ambulatory Care/ (36401) \\
\hline 2 serious mental disorder*.tw. (260) & 40 or/32-39 (268786) \\
\hline 3 serious psychiatric illness*.tw. (61) & Line 40 captures terms for primary care \\
\hline 4 serious psychiatric ill-health*.tw. (0) & 41 Quality Indicators, Health Care/ (10737) \\
\hline 5 serious mental ill-health*.tw. (0) & 42 (quality adj2 indicat*).tw. (6747) \\
\hline 6 serious psychiatric disorder*.tw. (130) & 43 (quality adj2 measure*).tw. (12491) \\
\hline 7 severe mental illness*.tw. (2679) & 44 (quality adj2 criteria).tw. (3829) \\
\hline 8 severe mental disorder*.tw. (720) & 45 (performance adj2 indicat*).tw. (4837) \\
\hline 9 severe mental ill-health*.tw. (2) & 46 (performance adj2 measure*).tw. (14194) \\
\hline 10 severe psychiatric illness*.tw. (128) & 47 (performance adj2 criteria).tw. (1367) \\
\hline 11 severe psychiatric disorder*.tw. (379) & 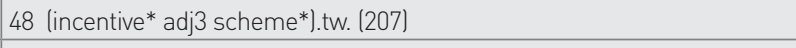 \\
\hline 12 severe psychiatric ill-health*.tw. (0) & 49 (incentive* adj3 assess*).tw. (96) \\
\hline 13 major mental disorder*.tw. (288) & 50 lincentive* adj3 measure*).tw. (152) \\
\hline 14 major mental illness*.tw. (350) & 51 lincentive* adj3 outcome*).tw. (96) \\
\hline 15 major psychiatric illness*.tw. (151) & 52 "Standard of Care"/ (1049) \\
\hline 16 major psychiatric ill-health*.tw. (0) & 53 (standard* adj2 care).tw. (25676) \\
\hline 17 major psychiatric disorder*.tw. (730) & 54 (standard* adj2 healthcare).tw. (400) \\
\hline 18 major mental ill-health*.tw. (0) & 55 “Quality of Health Care"/ (58460) \\
\hline $\begin{array}{l}19 \text { schizophrenia/ or schizophrenia, catatonic/ or schizophrenia, disorganized/ or } \\
\text { schizophrenia, paranoid/ or shared paranoid disorder/ (86432) }\end{array}$ & 56 (quality adj2 (healthcare or care)).tw. (39007) \\
\hline 20 (Schizophrenia* or schizophrenic or dementia praecox).tw. (90771) & 57 patient outcome assessment/ (934) \\
\hline 21 Schizotypal Personality Disorder/ (2217) & 58 (patient adj2 outcome assessment*).tw. (70) \\
\hline 22 (disorder* adj2 schizotypal).tw. (702) & 59 (patient adj2 outcome measure*).tw. (2492) \\
\hline 23 (disorder* adj1 delusional).tw. (703) & 60 proms.tw. (263) \\
\hline 24 Psychotic Disorders/ (32708) & 61 patient satisfaction/ or patient preference/ (63756) \\
\hline $\begin{array}{l}25 \text { (lpsychotic adj2 disorder*) or (schizoaffective adj2 disorder*) or psychoses } \\
\text { or psychosis or schizophreniform).tw. (38127) }\end{array}$ & 62 (patient* adj2 satisfaction).tw. (26024) \\
\hline 26 bipolar disorder/ or cyclothymic disorder/ (32171) & 63 (patient* adj2 experience*).tw. (59692) \\
\hline $\begin{array}{l}27 \text { (Bipolar adj2 (disorder* or depression or depressive or psychosis or } \\
\text { psychoses)).tw. (22038) }\end{array}$ & 64 (patient* adj2 preference*).tw. (8103) \\
\hline 28 (Manic state* or mania).tw. (8053) & 65 quality.tw. (594390) \\
\hline $\begin{array}{l}29 \text { (Manic adj2 (disorder* or depression or depressive or psychosis or } \\
\text { psychoses)).tw. (4445) }\end{array}$ & 66 or/41-65 (782974) \\
\hline $\begin{array}{l}30 \text { (cyclothymic disorder* or cyclothymic personalities or cyclothymic } \\
\text { personality).tw. (95) }\end{array}$ & Line 66 captures terms for quality indicators \\
\hline 31 or/1-30 (179930) & 6731 and 40 and 66 (551) \\
\hline Line 31 captures terms for serious mental illness & $\begin{array}{l}\text { Line } 67 \text { identifies records that contain at least one term for serious mental } \\
\text { illness, and at least one term for primary care and at least one term for } \\
\text { quality indicators }\end{array}$ \\
\hline 32 exp Primary Health Care/ (82203) & 68 limit 67 to yr="1990 -Current" (537) \\
\hline $\begin{array}{l}33 \text { general practitioners/ or physicians, family/ or physicians, primary care/ } \\
\text { (18403) }\end{array}$ & Line 68 applies the date limit \\
\hline \multicolumn{2}{|l|}{34 general practice/ or family practice/ (64455) } \\
\hline \multicolumn{2}{|l|}{35 (family adj2 pract*).tw. (11764) } \\
\hline \multicolumn{2}{|l|}{36 (primary adj2 care).tw. (89376) } \\
\hline \multicolumn{2}{|l|}{37 (general adj2 pract*).tw. (69034) } \\
\hline 38 (family adj2 physician*).tw. (12969) & \\
\hline
\end{tabular}




\section{Appendix 2. PRISMA checklist ${ }^{21}$ for systematic review of quality of care indicators for patients with serious mental illness}

\begin{tabular}{|c|c|c|c|}
\hline Section/topic & \# & Checklist item & $\begin{array}{l}\text { Reported } \\
\text { on page \# }\end{array}$ \\
\hline \multicolumn{4}{|l|}{ TITLE } \\
\hline Title & 1 & Identify the report as a systematic review, meta-analysis, or both. & 1 \\
\hline \multicolumn{4}{|l|}{ ABSTRACT } \\
\hline Structured summary & 2 & $\begin{array}{l}\text { Provide a structured summary including, as applicable: background; objectives; data sources; study eligibility } \\
\text { criteria, participants, and interventions; study appraisal and synthesis methods; results; limitations; conclusions } \\
\text { and implications of key findings; systematic review registration number. }\end{array}$ & 1 \\
\hline \multicolumn{4}{|l|}{ INTRODUCTION } \\
\hline Rationale & 3 & Describe the rationale for the review in the context of what is already known. & 1 \\
\hline Objectives & 4 & $\begin{array}{l}\text { Provide an explicit statement of questions being addressed with reference to participants, interventions, comparisons, } \\
\text { outcomes, and study design (PICOS). }\end{array}$ & N/A \\
\hline \multicolumn{4}{|l|}{ METHODS } \\
\hline Protocol and registration & 5 & $\begin{array}{l}\text { Indicate if a review protocol exists, if and where it can be accessed (for example, web address), and, if available, } \\
\text { provide registration information including registration number. }\end{array}$ & N/A \\
\hline Eligibility criteria & 6 & $\begin{array}{l}\text { Specify study characteristics (for example, PICOS, length of follow-up) and report characteristics (for example, } \\
\text { years considered, language, publication status) used as criteria for eligibility, giving rationale. }\end{array}$ & 2 \\
\hline Information sources & 7 & $\begin{array}{l}\text { Describe all information sources (for example, databases with dates of coverage, contact with study authors to } \\
\text { identify additional studies) in the search and date last searched. }\end{array}$ & 2 \\
\hline Search & 8 & Present full electronic search strategy for at least one database, including any limits used, such that it could be repeated. & 11 \\
\hline Study selection & 9 & $\begin{array}{l}\text { State the process for selecting studies (that is, screening, eligibility, included in systematic review, and, if applicable, } \\
\text { included in the meta-analysis). }\end{array}$ & 4 \\
\hline Data collection process & 10 & $\begin{array}{l}\text { Describe method of data extraction from reports (for example, piloted forms, independently, in duplicate) and any } \\
\text { processes for obtaining and confirming data from investigators. }\end{array}$ & 4 \\
\hline Data items & 11 & $\begin{array}{l}\text { List and define all variables for which data were sought (for example, PICOS, funding sources) and any assumptions } \\
\text { and simplifications made. }\end{array}$ & 5 \\
\hline $\begin{array}{l}\text { Risk of bias in individual } \\
\text { studies }\end{array}$ & 12 & $\begin{array}{l}\text { Describe methods used for assessing risk of bias of individual studies (including specification of whether this was } \\
\text { done at the study or outcome levell, and how this information is to be used in any data synthesis. }\end{array}$ & N/A \\
\hline Summary measures & 13 & State the principal summary measures (for example, risk ratio, difference in means). & N/A \\
\hline Synthesis of results & 14 & $\begin{array}{l}\text { Describe the methods of handling data and combining results of studies, if done, including measures of } \\
\text { consistency (for example, }\left.\right|^{2} \text { ) for each meta-analysis. }\end{array}$ & N/A \\
\hline Risk of bias across studies & 15 & $\begin{array}{l}\text { Specify any assessment of risk of bias that may affect the cumulative evidence (for example, publication bias, } \\
\text { selective reporting within studies). }\end{array}$ & N/A \\
\hline Additional analyses & 16 & $\begin{array}{l}\text { Describe methods of additional analyses (for example, sensitivity or subgroup analyses, meta-regression), if done, } \\
\text { indicating which were pre-specified. }\end{array}$ & N/A \\
\hline \multicolumn{4}{|l|}{ RESULTS } \\
\hline Study selection & 17 & $\begin{array}{l}\text { Give numbers of studies screened, assessed for eligibility, and included in the review, with reasons for exclusions at } \\
\text { each stage, ideally with a flow diagram. }\end{array}$ & 6 \\
\hline Study characteristics & 18 & $\begin{array}{l}\text { For each study, present characteristics for which data were extracted (for example, study size, PICOS, } \\
\text { follow-up period) and provide the citations. }\end{array}$ & 5 \\
\hline Risk of bias within studies & 19 & Present data on risk of bias of each study and, if available, any outcome level assessment (see item 12). & N/A \\
\hline $\begin{array}{l}\text { Results of individual } \\
\text { studies }\end{array}$ & 20 & $\begin{array}{l}\text { For all outcomes considered (benefits or harms), present, for each study: (a) simple summary data for each } \\
\text { intervention group; and (b) effect estimates and confidence intervals, ideally with a forest plot. }\end{array}$ & N/A \\
\hline Synthesis of results & 21 & Present results of each meta-analysis done, including confidence intervals and measures of consistency. & $\mathrm{N} / \mathrm{A}$ \\
\hline Risk of bias across studies & 22 & Present results of any assessment of risk of bias across studies (see Item 15). & N/A \\
\hline Additional analysis & 23 & Give results of additional analyses, if done (for example, sensitivity or subgroup analyses, meta-regression [see Item 16]). & N/A \\
\hline \multicolumn{4}{|l|}{ DISCUSSION } \\
\hline Summary of evidence & 24 & $\begin{array}{l}\text { Summarise the main findings including the strength of evidence for each main outcome; consider their relevance to } \\
\text { key groups (for example, healthcare providers, users, and policymakers). }\end{array}$ & 7 \\
\hline Limitations & 25 & $\begin{array}{l}\text { Discuss limitations at study and outcome level (for example, risk of bias), and at review level (for example, incomplete } \\
\text { retrieval of identified research, reporting bias). }\end{array}$ & 7 \\
\hline Conclusions & 26 & Provide a general interpretation of the results in the context of other evidence, and implications for future research. & 7 \\
\hline \multicolumn{4}{|c|}{ 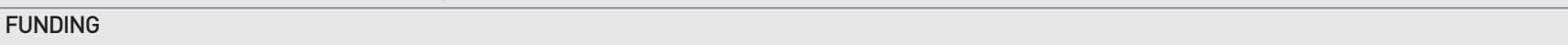 } \\
\hline Funding & 27 & $\begin{array}{l}\text { Describe sources of funding for the systematic review and other support (for example, supply of data); role of funders } \\
\text { for the systematic review. }\end{array}$ & 8 \\
\hline
\end{tabular}

